\title{
Probabilistic seismic hazard assessment in Greece - Part 3: Deaggregation
}

\author{
G-A. Tselentis and L. Danciu \\ University of Patras, Seismological Lab, Rio 265 00, Patras, Greece
}

Received: 5 November 2009 - Revised: 8 December 2009 - Accepted: 9 December 2009 - Published: 12 January 2010

\begin{abstract}
The present third part of the study, concerning the evaluation of earthquake hazard in Greece in terms of various ground motion parameters, deals with the deaggregation of the obtained results The seismic hazard maps presented for peak ground acceleration and spectral acceleration at $0.2 \mathrm{~s}$ and $1.0 \mathrm{~s}$, with $10 \%$ probability of exceedance in 50 years, were deaggregated in order to quantify the dominant scenario. There are three basic components of each dominant scenario: earthquake magnitude $(M)$, source-to-site distance $(R)$ and epsilon $(\varepsilon)$. We present deaggregation maps of mean and mode values of $\mathrm{M}-\mathrm{R}-\varepsilon$ triplet showing the contribution to hazard over a dense grid.
\end{abstract}

\section{Introduction}

From an earthquake design perspective, probabilistic seismic hazard assessment (PSHA), aggregates ground motion contributions from all the earthquakes of different magnitudes occurring at different source to site distances; but one does not know a priori whether the estimated ground motion at the site is due to contributions from closer, smaller events or from contributions from distant, larger events. The concept of deaggregation was introduced in order to highlight the relative contribution of events to the overall seismic hazard. Commonly the overall seismic hazard is deaggregated in terms of at least two variables: magnitude $(M)$ and sourceto-site distance $(R)$ (Chapman, 1995; McGuire and Shedlock, 1981; Stepp et al., 1993) With the aim of deaggregation, the predominant earthquake scenario can be generated and corresponding time-histories can be selected and/or simulated for use in advanced design of critical structures or detailed site effects (i.e. slope stability, liquefaction) analysis.

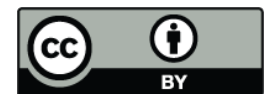

Correspondence to: G-A. Tselentis (tselenti@upatras.gr)
McGuire (1995) has defined the design or "beta" earthquake based on the deaggregation of the hazard with respect to the M-R pair and an additional variable referred as epsilon $(\varepsilon)$, defined as the number of standard deviations from the median ground motion predicted by an attenuation relationship. The calculation of the design or "beta" earthquake is based on the identification of the dominant seismic source and its associated M-R- $\varepsilon$ triplet to generate the target uniform hazard spectrum.

To understand the relative contribution of seismic sources to the overall hazard Bazzurro and Cornell (1999), introduced deaggregation of the seismic hazard in terms of latitude and longitude, rather than distance and referred this as geographical hazard deaggregation. Such geographical deaggregation, or 4-D $\left(M-\phi^{\circ}-\lambda^{\circ}-\varepsilon\right)$ deaggregation, provides the spatial distribution of the predominant sources of seismic hazard (Halchuck and Adams, 2004; Halchuck et al., 2007; Harmsen and Frankel, 2001; Montilla et al., 2002).

Maps depicting the spatial distribution of $M, R$ or $\varepsilon$ were found to be useful for comparing probabilistic ground motions with ground motion from scenario earthquakes on dominant faults (Cramer and Petersen, 1996; Harmsen, 2002). The deaggregation process can be also extended to analize loss estimation (Cao, 2007), breaking down the loss curve into short-term, medium-term, and long-term losses. These measures are not limited to single site assessments, but all can be evaluated for geographically distributed portfolios, and they are useful to risk managers who are seeking to mitigate against possible losses (Smith, 2008).

Recently, Pagani and Marcellini (2007) have proposed a new PSHA deaggregation technique that considers the number of earthquake occurrences in addition to the usually adopted M-R- $\varepsilon$ triplet. The technique relies on two aspects: (i) deaggregation is made in terms of probabilities and (ii) the contributions to the deaggregation hazard values are given by single or multiple earthquake occurrences. 
The technique was tested for three different source models: a single point source, gridded seismicity and a vertical fault and offers interesting insights into the mechanism of hazard computation. The fault example provided evidences that in high-seismicity regions the final hazard values are dominated by the occurrence of multiple events, whereas the gridded seismicity example suggested the dominance of single occurrence on the hazard values.

Formally, a deaggregation process implies the computation of the fractional contributions of different scenario groups that contribute to the global hazard at a given return period. In practice this is achieved by grouping together similar scenarios in bins and express them as probabilistic density (or mass) functions of magnitude, distance and other variables, such as $\varepsilon$. During deaggregation process, the relative contribution to the hazard of each bin is calculated by dividing the bin exceedance frequency by the total exceedance frequency of all bins. The mathematical expression of the deaggregation process is given by:

$$
\begin{aligned}
& \operatorname{Deagg}\left(Y>y^{*}, m^{\circ}<M<m^{u}, r_{\min }<R<r_{\max }\right)= \\
& \frac{\sum_{i=1}^{N_{\text {sources }}} \lambda\left(m_{\mathrm{i}}\right) \int_{M=m^{\circ} r_{\mathrm{i}}=r_{\min }}^{m^{u}} \int_{\min }^{r_{\max }} P\left[Y>y^{*} \mid m, r, \varepsilon\right] f_{\mathrm{M}}(m)_{\mathrm{i}} f_{R}(r \mid m)_{\mathrm{i}} f_{E}(\varepsilon)_{\mathrm{i}} d m d r d \varepsilon}{v_{Y}\left(Y>y^{*}\right)}
\end{aligned}
$$

where $\lambda\left(m_{\mathrm{i}}\right)$ is the frequency of earthquakes on seismic sources " $i$ " above a minimum magnitude of engineering significance $\left(m^{\circ}\right) ; P\left[Y \geq y^{*} \mid m, r, \varepsilon\right]$ is the probability that, given a magnitude $M_{\mathrm{i}}$ earthquake at a distance $R_{\mathrm{i}}$ from the site, the ground motion exceeds a value $y^{*} ; f_{\mathrm{M}}(m)_{\mathrm{i}}$ represents the probability density function associated to the likelihood of magnitude of events $\left(m_{\mathrm{i}}<M_{\mathrm{i}}<m_{\mathrm{i}}^{\mathrm{u}}\right)$ occurring in source "i"; $f_{R}(r \mid m)_{\mathrm{i}}$ is the conditional probability density function used to describe the randomness epicenter locations within each source " $\mathrm{i}$ "; and $f_{\mathrm{E}}(\varepsilon)_{\mathrm{i}}$ is the probability density function of $\varepsilon$; and $v_{Y}\left(y^{*}\right)$ is the annual frequency of exceeding ground motion level $y^{*}$.

Equation (1) yields the bin with the largest relative contribution to the total hazard, as the dominant or controlling scenario(s). The identified dominant scenario is commonly defined in terms of two statistical descriptors - mean or modal - of the joint contribution (magnitude, distance or other parameters). Another statistical descriptor commonly used in PSHA is the median. From the statistical point of view, the mean is the arithmetic average of a set of data. The median is the value for which half the observations are smaller and half larger. The mode is the most frequent value. It should be acknowledged that these average descriptors do not lead to the same value, unless a normal distribution is considered.

In the deaggregation context, among the two average descriptors, the mode is considered as a better descriptor of a realistic dominant scenario, particularly for regions exhibiting more than one significant seismic sources. The mode gives the most likely value of magnitude, distance or other parameter that may contribute to a specified ground motion level. The disadvantage of using mode values is that they are variant with respect to binning schemes, and therefore not so robust.

Alternatively, the mean is simple to compute, invariant with respect to binning schemes but may not provide values corresponding to a plausible earthquake scenario. Therefore, it is obvious that the output of hazard deaggregation is bin dependent, and the selection of the width of each bin represents an important aspect in seismic hazard deaggregation. From the bin size perspective, the commonly constrain is that the width of each bin should be defined in the same way as during the numerical integration of PSHA. Generally, the magnitude intervals are constant and the distance interval increasing with distance from the site, thus the interval values or binning schemes are arbitrary defined by engineers conducting the analysis (Abrahamson, 2006).

In the present study, the seismic hazard calculation conducted for Greece in terms of various ground motion parameters (Tselentis and Danciu, 2010; Tselentis et al., 2010), is deaggregated in order to identify the contribution of various sources to the final hazard results. The seismic hazard was deaggregated following the methodology proposed by Bazzurro (1998) and Bazzurro and Cornell (1999) and we have deaggregated the seismic hazard in terms of the M-R$\varepsilon$ triplet, called 3-D deaggregation. Regarding the ground motion parameters, our attention was focused on the peak ground acceleration (PGA) and spectral acceleration (SA) due to their importance on seismic design. The response periods of $0.2 \mathrm{~s}$ and $1 \mathrm{~s}$ were selected for the deaggregation of SA.

The PSHA was carried out for the region of Greece following the classical PSHA methodology introduced by Cornell (1968) and improved by Esteva (1970). Temporal occurrences of earthquake, as well as the occurrence of ground motion at a site in excess of a specified level were represented by a Poisson process. The estimation of seismic hazard relied on the seismogenic sources, represented as areal sources and their associated seismicity parameters defined by Papazachos and Papaioannou (2000). The minimum magnitude used was 5.0, defined in terms of moment magnitude, whereas the maximum magnitude considered was the maximum observed magnitude plus a half magnitude unit.

Several ground motion predictive equations, or commonly referred attenuation relationships, were used for each ground motion parameter in order to account for the epistemic uncertainty associated with the ground motion prediction. These predictive equations are more likely to be valid for the region under investigation and their associated weights must sum to 1 .

The calculation of seismic hazard in terms of PGA was performed considering three predictive models: Danciu and Tselentis (2007), referred as DT07a, Margaris et al. (2002), referred as MA02 and Skarlatoudis et al. (2003), referred as SK03. In the initial PSHA computation, the predictive ground models DT07a and SK03 were credited with a $35 \%$ 
Table 1. Binning scheme used in PSHA deaggregation.

\begin{tabular}{ccc}
\hline \multirow{2}{*}{$\begin{array}{c}R \\
(\mathrm{~km})\end{array}$} & \multicolumn{2}{c}{ Binning scheme } \\
\cline { 2 - 3 } & $\begin{array}{c}\text { Distance } \\
(\mathrm{km})\end{array}$ & Magnitude \\
\hline $0-10$ & 0.1 & 0.25 \\
$10-20$ & 0.5 & 0.25 \\
$20-50$ & 1.0 & 0.25 \\
$50-100$ & 5 & 0.25 \\
$100-200$ & 10 & 0.25 \\
$200-300$ & 20 & 0.25 \\
\hline
\end{tabular}

weight, because they were making a distinction between different fault mechanisms, whereas the MA02 was assigned with a $30 \%$ weight. As in the case of PGA, the seismic hazard computation in terms of spectral acceleration, was performed considering two ground motion predictive models: Danciu and Tselentis (2007), referred as DT07b and Ambraseys et al. (2005), referred as AM05. A slightly different weight was assigned to each predictive model: 55\% DT07b and $45 \%$ for AM05.

The aleatory uncertainty associated to ground motion was accounted for, by integrating into the PSHA calculation the ground motion variability that is, the standard deviation associated to each ground motion model. A uniform level of truncation, equal to 3, was assigned to each ground motion predictive equation. The PSHA computation was carried out over a grid of points equally spaced at $10 \mathrm{~km}$, for a uniform rock soil condition and a unique return period of 475 years (probability of exceedance of $10 \%$ in 50 years). Next, the determined seismic hazard was deaggregated for each ground motion predictive equations and for the corresponding level of ground motion. The final deaggregation results at each grid point were determined by re-assembling the deaggregation results according to the weighting scheme associated to each ground motion model.

The same bins of magnitude and source to site distance were used to calculate the deaggregation as in the case of calculating the seismic hazard. The moment magnitude $M$, was binned into intervals of width $0.25 \mathrm{M}$, for source to site epicentral distance $R$ and the binning scheme is presented in Table 1. The hazard with respect to $\varepsilon$ was binned into intervals of width $0.2 \varepsilon$. Both mean and mode values of deaggregation in terms of magnitude, distance, latitude-longitude, as well as $\varepsilon$ were determined.

\section{3-D deaggregation results}

The seismic hazard was deaggregated in terms of the M-R$\varepsilon$ triplet and reported for mean $(\bar{M}, \bar{R}$, and $\bar{\varepsilon})$ and mode $(\widehat{M}$, $\widehat{R}$ and $\widehat{\varepsilon}$ ) values, associated with a corresponding 475 years return period or $10 \% 50$ year probability of exceedance. Fi-
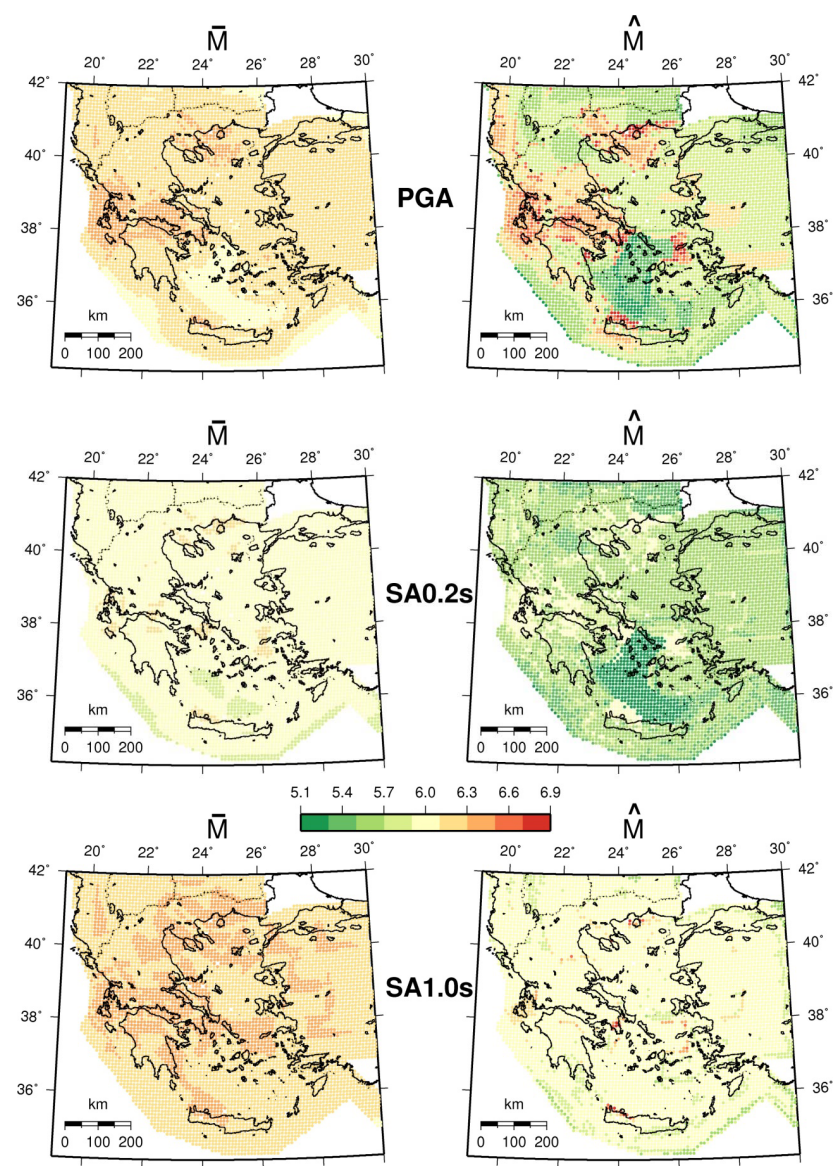

Fig. 1. Mean (column 1) and Modal (column 2) magnitudes as a function of PGA; SA(0.2 s) and SA(1.0 s).

gures 1,2 , and 3 present respectively the spatial distribution of the $\bar{M}, \bar{R}$, and $\bar{\varepsilon}$ and ( $\widehat{M}, \widehat{R}$ and $\widehat{\varepsilon}$ ) values over the entire region of investigation, as resulted from disaggregating in terms of median PGA and SA at two spectral values, the short-period value corresponding to $0.2 \mathrm{~s}$ and the long-period value corresponding to $1.0 \mathrm{~s}$. The geographical distribution of the magnitude presented in Fig. 1, shows the differences between the $\bar{M}$ and $\widehat{M}$ values, as well as the differences between the magnitude trend at short $(0.2 \mathrm{~s})$ and intermediate $(1.0 \mathrm{~s})$ periods. We can observe that the deaggregation results follow the seismicity pattern, particularly for the mean values. This trend was expected, due to the fact that the present seismic hazard calculation was based on homogeneous seismotectonic zones.

At short periods, such as $0.2 \mathrm{~s}$, the seismic hazard in Greece is dominated by scenarios of moderate magnitude of about $5.7 \mathrm{M}$ to $6.1 \mathrm{M}$, most likely to occur at very close source-to-site distances, within a distance range of $0-40 \mathrm{~km}$. At intermediate periods, such as $1.0 \mathrm{~s}$, the seismic hazard is governed by scenarios of $6.0 \mathrm{M}$ to $6.7 \mathrm{M}$ and quite larger distance range, $0-80 \mathrm{~km}$. Further investigation of these maps 

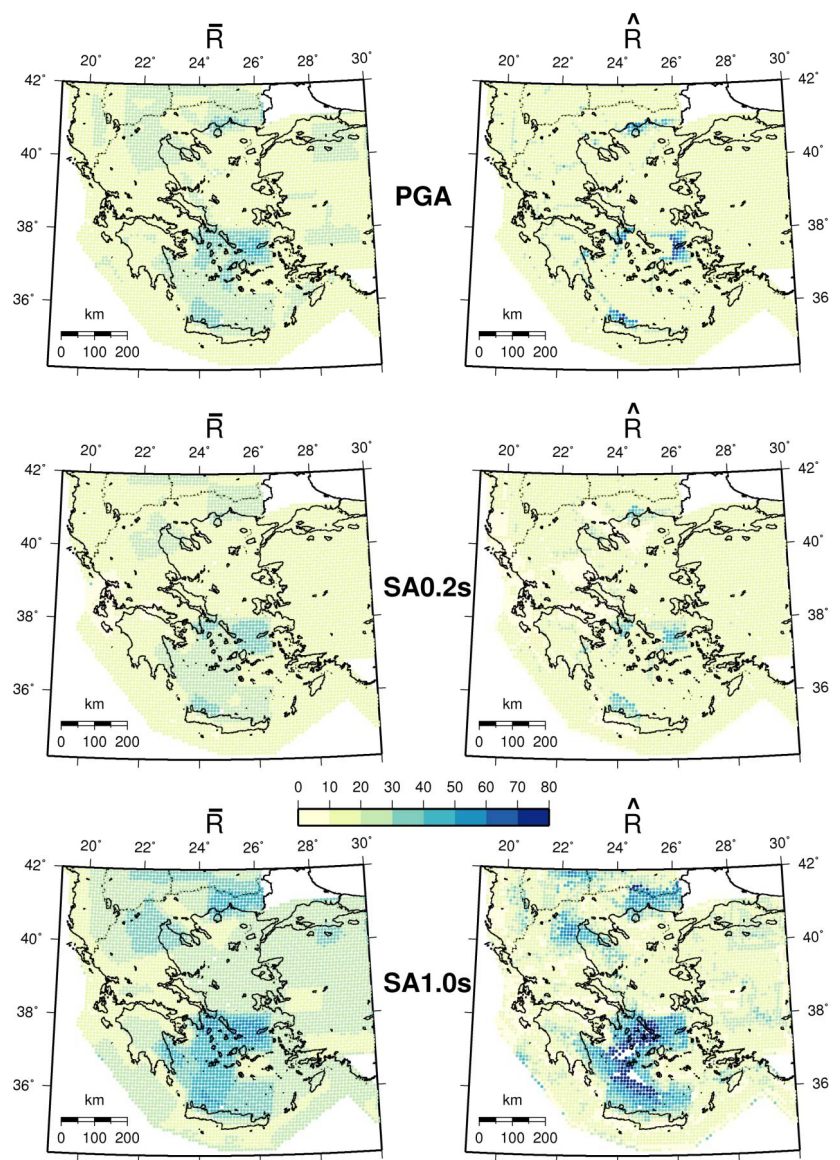

Fig. 2. Mean (column 1) and Modal (column 2) distances as a function of PGA; $\mathrm{SA}(0.2 \mathrm{~s})$ and $\mathrm{SA}(1.0 \mathrm{~s})$.

reveals that the distribution of the mean values is more uniform over the region, following the seismicity path modeled by the seismogenic sources. On the other hand, the distribution of the mode values is not uniform over the region, but still dependent on the seismogenic sources. Generally, the $\bar{M}$ values are larger than the $\widehat{M}$ values, and the general trend is that both $\bar{M}$ and $\widehat{M}$ values are increasing with period. Although, PGA is equivalent to the spectral acceleration at zero period, the observed magnitude trend is not obvious when the maps of $\bar{M}$ and $\widehat{M}$ are compared. The $\widehat{M}$ values in case of PGA, are exhibiting slightly larger than $\bar{M}$ values, particularly on those regions of high seismicity, such as, Ionian Islands, Central Greece, Western Crete Island, and Northern Greece.

The deaggregation results in the region of Ionian Islands, shows that the $\bar{M}$ and $\widehat{M}$ values for spectral accelerations at the two periods of interest $(0.2 \mathrm{~s}$ and $1.0 \mathrm{~s})$ are very similar. Therefore, for regions of high seismicity, the dominant events might be selected from both $\bar{M}$ and $\widehat{M}$ values. These dominant events are needed to be defined in terms of sourceto-site distance. The investigation of the mapped $\bar{R}$ and $\widehat{R}$
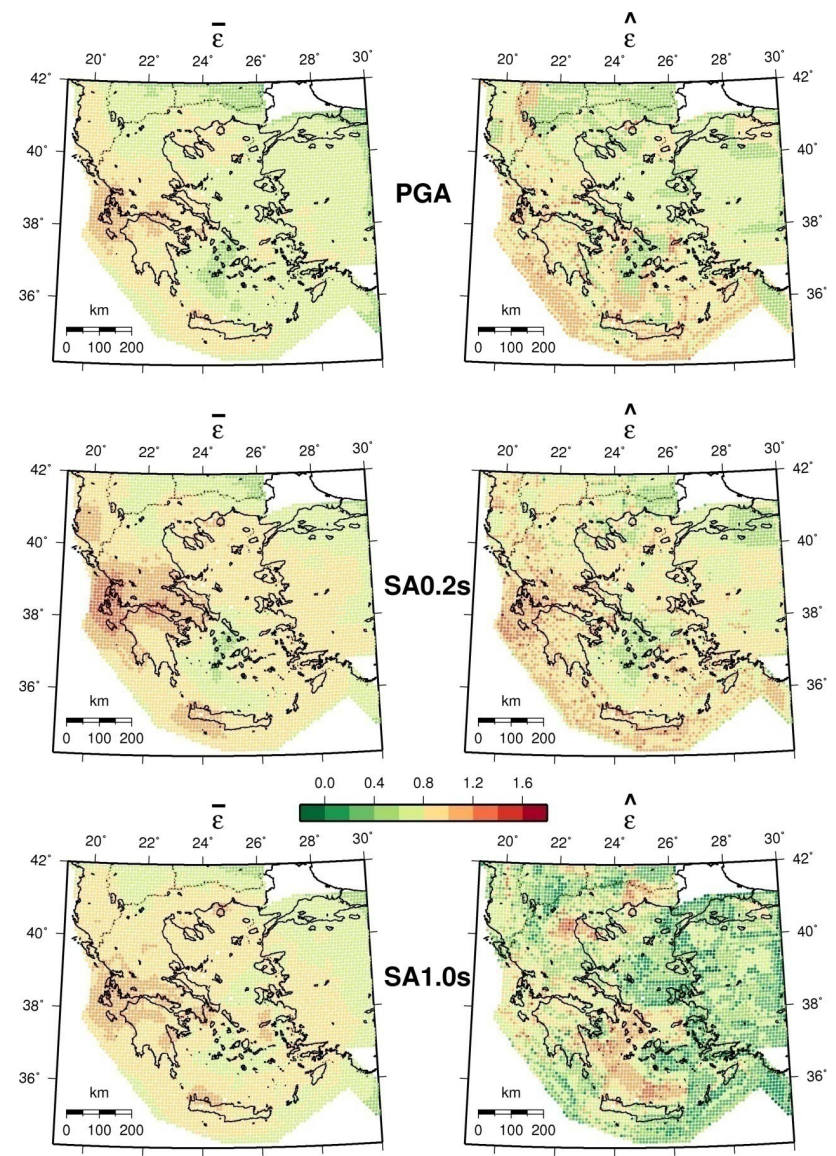

Fig. 3. Mean (column 1) and Modal (column 2) epsilons as a function of PGA; SA(0.2 s) and SA(1.0 s).

values, presented in Fig. 2 shows a similarity as in the case of $\bar{M}$ and $\widehat{M}$ values. Typically, both $\bar{R}$ and $\widehat{R}$ values are increasing as the period increases from $0.2 \mathrm{~s}$ to $1.0 \mathrm{~s}$. Again, it can be observed that the $\bar{R}$ and $\widehat{R}$ values for very high seismic regions, such as the Ionian Islands, are close related to each other, particularly at short periods $(0.2 \mathrm{~s})$ and PGA. For the same region, slight differences might be observed at longer periods, at $1.0 \mathrm{~s}$ respectively, where the $\bar{R}$ values are larger than $\widehat{R}$ values, however the difference is not significant. The increasing of the mean and mode magnitude and distance with increasing response period is a general behavior for uni-modal deaggregation plots (Harmsen et al., 1999).

In the region of Cyclades Islands, it can be observed that both $\bar{R}$ and $\widehat{R}$ values are larger than for the other regions. In this region, of low seismicity, the hazard contribution is influenced by the high seismicity rates of the surrounded seismogenic sources. For instance, the Cyclades Islands region comprises three seismogenic sources which represent regions of low occurrence rate and the observed magnitude are bellow 6.3 M.The surrounding seismogenic sources, all have high seismicity rates and large observed and expected 
Table 2a. Deaggregation results for PGA.

\begin{tabular}{|c|c|c|c|c|c|c|c|c|c|}
\hline Lat & Long & Cities & 50th & $\bar{M}$ & $\bar{R}$ & $\bar{\varepsilon}$ & $\widehat{M}$ & $\widehat{R}$ & $\widehat{\varepsilon}$ \\
\hline 23.72 & 37.97 & Athens & 0.23 & 6.367 & 24.172 & 0.983 & 6.319 & 18.382 & 0.802 \\
\hline 22.95 & 40.64 & Thessaloniki & 0.23 & 6.315 & 24.296 & 0.857 & 6.522 & 20.222 & 0.452 \\
\hline 21.73 & 38.25 & Patras & 0.36 & 6.304 & 15.534 & 0.995 & 6.432 & 16.240 & 0.925 \\
\hline 25.13 & 35.34 & Iraklion & 0.20 & 6.119 & 25.867 & 0.770 & 5.678 & 12.265 & 0.626 \\
\hline 22.42 & 39.64 & Larissa & 0.32 & 6.253 & 17.324 & 0.827 & 6.36 & 11.400 & 0.733 \\
\hline 22.93 & 39.36 & Volos & 0.38 & 6.270 & 14.642 & 0.830 & 6.120 & 10.000 & 0.801 \\
\hline 20.86 & 39.67 & Ioannina & 0.26 & 6.246 & 17.577 & 0.908 & 6.006 & 9.984 & 0.775 \\
\hline 24.41 & 40.94 & Kavala & 0.18 & 6.294 & 31.266 & 0.837 & 6.560 & 39.079 & 0.894 \\
\hline 22.93 & 37.94 & Korinth & 0.40 & 6.292 & 12.932 & 0.953 & 6.212 & 10.000 & 0.860 \\
\hline 25.87 & 40.85 & Alexandroupolis & 0.21 & 6.222 & 22.297 & 0.712 & 6.119 & 12.402 & 0.455 \\
\hline 25.40 & 41.12 & Komotini & 0.16 & 6.178 & 29.656 & 0.634 & 5.638 & 10.463 & 0.400 \\
\hline 24.88 & 41.13 & Xanthi & 0.15 & 6.185 & 30.019 & 0.656 & 5.615 & 9.872 & 0.399 \\
\hline 24.15 & 41.15 & Drama & 0.24 & 6.167 & 19.425 & 0.648 & 5.881 & 9.989 & 0.504 \\
\hline 23.55 & 41.09 & Serres & 0.28 & 6.317 & 20.504 & 0.853 & 6.302 & 12.013 & 0.458 \\
\hline 22.87 & 40.99 & Kilkis & 0.40 & 6.279 & 12.802 & 0.786 & 6.343 & 10.000 & 0.444 \\
\hline 23.44 & 40.37 & Polygyros & 0.24 & 6.299 & 24.134 & 0.877 & 6.129 & 11.015 & 0.610 \\
\hline 24.24 & 40.25 & Karyai & 0.40 & 6.316 & 13.685 & 0.831 & 6.380 & 9.999 & 0.399 \\
\hline 22.04 & 40.80 & Edessa & 0.18 & 6.141 & 20.682 & 0.650 & 5.769 & 10.000 & 0.556 \\
\hline 22.20 & 40.52 & Veroia & 0.17 & 6.122 & 23.072 & 0.653 & 5.620 & 10.001 & 0.598 \\
\hline 22.50 & 40.27 & Katerni & 0.18 & 6.122 & 23.477 & 0.656 & 5.620 & 9.999 & 0.600 \\
\hline 21.40 & 40.78 & Florina & 0.19 & 6.157 & 20.616 & 0.684 & 5.880 & 9.999 & 0.400 \\
\hline 21.79 & 40.30 & Kozani & 0.17 & 6.138 & 23.928 & 0.677 & 5.620 & 9.999 & 0.602 \\
\hline 21.27 & 40.52 & Kastoria & 0.21 & 6.143 & 19.850 & 0.702 & 5.768 & 10.257 & 0.692 \\
\hline 21.42 & 40.08 & Grevena & 0.22 & 6.108 & 17.469 & 0.738 & 5.880 & 9.969 & 0.591 \\
\hline 20.98 & 39.16 & Arta & 0.43 & 6.357 & 11.173 & 1.041 & 6.379 & 9.988 & 0.945 \\
\hline 20.27 & 39.50 & Igoumenitsa & 0.29 & 6.238 & 15.371 & 0.863 & 6.120 & 10.001 & 0.599 \\
\hline 20.75 & 38.96 & Preveza & 0.42 & 6.376 & 11.947 & 1.123 & 6.604 & 9.998 & 0.626 \\
\hline 22.56 & 40.59 & Trikala & 0.18 & 6.203 & 25.620 & 0.755 & 5.669 & 9.937 & 0.651 \\
\hline 21.92 & 39.36 & Karditsa & 0.36 & 6.264 & 14.376 & 0.860 & 6.120 & 10.000 & 0.796 \\
\hline 23.60 & 38.46 & Halkis & 0.42 & 6.276 & 13.028 & 0.901 & 6.356 & 10.000 & 0.457 \\
\hline 22.43 & 38.90 & Lamia & 0.36 & 6.293 & 15.164 & 0.896 & 6.164 & 10.004 & 0.733 \\
\hline 22.88 & 38.43 & Levadia & 0.44 & 6.363 & 12.613 & 0.979 & 6.380 & 9.993 & 0.736 \\
\hline 22.38 & 38.53 & Amfissa & 0.45 & 6.364 & 12.084 & 1.068 & 6.543 & 10.075 & 0.604 \\
\hline 21.79 & 38.91 & Karpenision & 0.33 & 6.262 & 15.512 & 0.873 & 6.116 & 9.920 & 0.721 \\
\hline 21.43 & 38.37 & Messolongion & 0.36 & 6.277 & 15.622 & 0.931 & 6.029 & 9.935 & 0.862 \\
\hline 22.81 & 37.57 & Nafplio & 0.28 & 6.257 & 19.348 & 0.899 & 6.180 & 13.204 & 0.615 \\
\hline 21.44 & 37.67 & Prgos & 0.30 & 6.316 & 19.546 & 0.994 & 6.056 & 10.391 & 0.747 \\
\hline 22.37 & 37.51 & Tripoli & 0.26 & 6.162 & 17.467 & 0.823 & 5.784 & 9.989 & 0.929 \\
\hline 22.43 & 37.07 & Sparta & 0.24 & 6.176 & 21.519 & 0.858 & 5.942 & 12.696 & 0.725 \\
\hline 22.11 & 37.04 & Kalamata & 0.29 & 6.227 & 17.135 & 0.879 & 6.027 & 10.000 & 0.678 \\
\hline 25.71 & 35.19 & Agios & 0.24 & 6.119 & 21.731 & 0.796 & 5.740 & 12.424 & 0.807 \\
\hline 24.47 & 35.37 & Rethimno & 0.22 & 6.296 & 30.853 & 0.977 & 6.376 & 28.525 & 0.890 \\
\hline 24.02 & 35.51 & Chania & 0.23 & 6.329 & 32.080 & 1.009 & 6.273 & 29.226 & 1.099 \\
\hline 26.55 & 39.11 & Mythilini & 0.30 & 6.214 & 17.715 & 0.715 & 5.939 & 10.000 & 0.551 \\
\hline 26.14 & 38.36 & Xios & 0.25 & 6.155 & 17.685 & 0.705 & 5.880 & 10.002 & 0.600 \\
\hline 26.97 & 37.76 & Samos & 0.26 & 6.195 & 17.658 & 0.729 & 5.880 & 10.000 & 0.600 \\
\hline 24.94 & 37.44 & Ermoupolis & 0.11 & 6.032 & 28.942 & 0.520 & 5.380 & 10.000 & 0.400 \\
\hline 28.23 & 36.44 & Rodos & 0.26 & 6.143 & 18.609 & 0.767 & 5.845 & 9.243 & 0.625 \\
\hline 19.92 & 39.62 & Kerkyra & 0.22 & 6.212 & 14.019 & 0.823 & 6.125 & 10.059 & 0.597 \\
\hline 20.48 & 38.18 & Argostolion & 0.54 & 6.430 & 10.930 & 1.117 & 6.378 & 10.000 & 1.003 \\
\hline 20.71 & 38.83 & Lefkas & 0.43 & 6.381 & 12.151 & 1.118 & 6.394 & 10.000 & 0.976 \\
\hline 20.90 & 37.79 & Zakynthos & 0.46 & 6.392 & 11.066 & 1.097 & 6.537 & 10.001 & 0.743 \\
\hline
\end{tabular}


Table 2b. Deaggregation of the PSHA results in terms of SA(0.2 s).

\begin{tabular}{|c|c|c|c|c|c|c|c|c|c|}
\hline Lat & Long & Cities & $\mathrm{SA}(0.2 \mathrm{~s})$ & $\bar{M}$ & $\bar{R}$ & $\bar{\varepsilon}$ & $\widehat{M}$ & $\widehat{R}$ & $\widehat{\varepsilon}$ \\
\hline 23.72 & 37.97 & Athens & 0.59 & 6.13 & 22.04 & 1.12 & 5.86 & 15.72 & 0.99 \\
\hline 22.95 & 40.64 & Thessaloniki & 0.58 & 6.11 & 21.75 & 0.98 & 5.97 & 16.65 & 0.74 \\
\hline 21.73 & 38.25 & Patras & 0.84 & 6.04 & 13.34 & 1.09 & 5.88 & 13.05 & 1.14 \\
\hline 25.13 & 35.34 & Iraklion & 0.56 & 5.95 & 22.08 & 0.84 & 5.43 & 11.24 & 0.79 \\
\hline 22.42 & 39.64 & Larissa & 0.76 & 6.04 & 15.25 & 0.98 & 5.69 & 8.93 & 0.84 \\
\hline 22.93 & 39.36 & Volos & 0.89 & 6.04 & 12.29 & 1.00 & 5.67 & 5.50 & 0.80 \\
\hline 20.86 & 39.67 & Ioannina & 0.66 & 6.03 & 15.65 & 0.98 & 5.85 & 15.09 & 0.99 \\
\hline 24.41 & 40.94 & Kavala & 0.48 & 6.13 & 27.61 & 0.87 & 6.01 & 29.89 & 0.81 \\
\hline 22.93 & 37.94 & Korinth & 1.34 & 6.05 & 11.24 & 1.10 & 5.85 & 6.21 & 0.78 \\
\hline 25.87 & 40.85 & Alexandroupolis & 0.67 & 6.04 & 20.65 & 0.81 & 5.68 & 14.37 & 0.74 \\
\hline 25.40 & 41.12 & Komotini & 0.42 & 6.04 & 27.03 & 0.67 & 5.42 & 10.42 & 0.41 \\
\hline 24.88 & 41.13 & Xanthi & 0.42 & 6.04 & 26.80 & 0.68 & 5.44 & 11.60 & 0.50 \\
\hline 24.15 & 41.15 & Drama & 0.59 & 6.00 & 16.83 & 0.75 & 5.54 & 9.95 & 0.78 \\
\hline 23.55 & 41.09 & Serres & 0.70 & 6.10 & 18.00 & 0.96 & 5.96 & 16.90 & 0.86 \\
\hline 22.87 & 40.99 & Kilkis & 0.93 & 6.04 & 11.05 & 0.96 & 5.81 & 5.48 & 0.68 \\
\hline 23.44 & 40.37 & Polygyros & 0.62 & 6.11 & 21.39 & 0.98 & 6.06 & 23.99 & 1.06 \\
\hline 24.24 & 40.25 & Karyai & 1.35 & 6.07 & 11.86 & 0.97 & 5.81 & 5.51 & 0.62 \\
\hline 22.04 & 40.80 & Edessa & 0.47 & 5.97 & 18.24 & 0.74 & 5.65 & 14.84 & 0.86 \\
\hline 22.20 & 40.52 & Veroia & 0.44 & 5.98 & 20.13 & 0.73 & 5.40 & 9.99 & 0.80 \\
\hline 22.50 & 40.27 & Katerini & 0.45 & 5.97 & 20.46 & 0.73 & 5.40 & 10.00 & 0.80 \\
\hline 21.40 & 40.78 & Florina & 0.49 & 5.98 & 18.37 & 0.78 & 5.63 & 13.68 & 0.82 \\
\hline 21.79 & 40.30 & Kozani & 0.44 & 5.99 & 20.66 & 0.75 & 5.42 & 10.00 & 0.77 \\
\hline 21.27 & 40.52 & Kastoria & 0.51 & 5.96 & 17.45 & 0.81 & 5.59 & 10.99 & 0.78 \\
\hline 21.42 & 40.08 & Grevena & 0.53 & 5.95 & 15.36 & 0.82 & 5.58 & 10.49 & 0.85 \\
\hline 20.98 & 39.16 & Arta & 1.39 & 6.07 & 9.08 & 1.22 & 5.94 & 5.49 & 0.85 \\
\hline 20.27 & 39.50 & Igoumenitsa & 1.01 & 6.01 & 13.25 & 1.00 & 5.60 & 5.51 & 0.77 \\
\hline 20.75 & 38.96 & Preveza & 1.45 & 6.09 & 9.65 & 1.24 & 6.04 & 9.02 & 1.02 \\
\hline 22.56 & 40.59 & Trikala & 0.46 & 6.03 & 22.14 & 0.80 & 5.63 & 13.72 & 0.73 \\
\hline 21.92 & 39.36 & Karditsa & 0.83 & 6.02 & 12.02 & 1.03 & 5.76 & 8.78 & 0.89 \\
\hline 23.60 & 38.46 & Halkis & 0.94 & 6.04 & 11.22 & 1.06 & 5.76 & 5.64 & 0.82 \\
\hline 22.43 & 38.90 & Lamia & 0.84 & 6.04 & 12.55 & 1.05 & 5.72 & 7.31 & 0.85 \\
\hline 22.88 & 38.43 & Levadia & 1.22 & 6.06 & 11.01 & 1.16 & 5.80 & 6.37 & 1.00 \\
\hline 22.38 & 38.53 & Amfissa & 1.33 & 6.08 & 10.36 & 1.21 & 5.94 & 7.04 & 0.95 \\
\hline 21.79 & 38.91 & Karpenision & 0.78 & 6.03 & 13.30 & 1.01 & 5.74 & 11.10 & 1.11 \\
\hline 21.43 & 38.37 & Messolongion & 0.82 & 6.02 & 13.05 & 1.07 & 5.69 & 10.59 & 1.18 \\
\hline 22.81 & 37.57 & Nafplio & 0.76 & 6.03 & 16.92 & 1.00 & 5.81 & 12.32 & 0.84 \\
\hline 21.44 & 37.67 & Pyrgos & 0.80 & 6.06 & 17.47 & 1.06 & 5.96 & 17.83 & 1.02 \\
\hline 22.37 & 37.51 & Tripoli & 0.63 & 5.96 & 15.48 & 0.91 & 5.54 & 10.00 & 0.99 \\
\hline 22.43 & 37.07 & Sparta & 0.61 & 5.99 & 19.33 & 0.95 & 5.64 & 12.13 & 0.87 \\
\hline 22.11 & 37.04 & Kalamata & 0.76 & 6.01 & 14.95 & 1.00 & 5.65 & 9.61 & 1.01 \\
\hline 25.71 & 35.19 & Agios & 0.74 & 5.94 & 19.46 & 0.90 & 5.58 & 11.33 & 0.85 \\
\hline 24.47 & 35.37 & Rethimno & 0.73 & 6.11 & 27.96 & 1.07 & 5.85 & 24.54 & 1.20 \\
\hline 24.02 & 35.51 & Chania & 0.79 & 6.13 & 29.50 & 1.10 & 5.89 & 28.55 & 1.26 \\
\hline 26.55 & 39.11 & Mythilini & 0.75 & 6.02 & 15.44 & 0.87 & 5.57 & 10.00 & 0.93 \\
\hline 26.14 & 38.36 & Xios & 0.61 & 5.98 & 15.98 & 0.82 & 5.54 & 10.00 & 0.87 \\
\hline 26.97 & 37.76 & Samos & 0.63 & 5.99 & 15.64 & 0.87 & 5.57 & 10.00 & 0.93 \\
\hline 24.94 & 37.44 & Ermoupolis & 0.29 & 5.91 & 25.44 & 0.56 & 5.26 & 10.00 & 0.51 \\
\hline 28.23 & 36.44 & Rodos & 0.84 & 5.97 & 16.38 & 0.87 & 5.53 & 9.31 & 0.92 \\
\hline 19.92 & 39.62 & Kerkyra & 0.79 & 5.98 & 12.26 & 0.96 & 5.54 & 5.50 & 0.82 \\
\hline 20.48 & 38.18 & Argostolion & 1.99 & 6.08 & 8.94 & 1.37 & 5.95 & 5.50 & 1.07 \\
\hline 20.71 & 38.83 & Lefkas & 1.53 & 6.10 & 9.74 & 1.26 & 5.92 & 6.56 & 1.00 \\
\hline 20.90 & 37.79 & Zakynthos & 1.62 & 6.10 & 8.67 & 1.31 & 5.88 & 5.45 & 1.09 \\
\hline
\end{tabular}


Table 2c. Deaggregation of the PSHA results for SA(1.0 s).

\begin{tabular}{|c|c|c|c|c|c|c|c|c|c|}
\hline Lat & Long & Cities & $\mathrm{SA}(1.0 \mathrm{~s})$ & $\bar{M}$ & $\bar{R}$ & $\bar{\varepsilon}$ & $\widehat{M}$ & $\widehat{R}$ & $\widehat{\varepsilon}$ \\
\hline 23.72 & 37.97 & Athens & 0.30 & 6.41 & 29.52 & 1.091 & 6.10 & 17.98 & 1.001 \\
\hline 22.95 & 40.64 & Thessaloniki & 0.30 & 6.38 & 28.99 & 0.968 & 6.13 & 18.97 & 0.677 \\
\hline 21.73 & 38.25 & Patras & 0.43 & 6.31 & 18.03 & 1.011 & 6.06 & 13.23 & 0.827 \\
\hline 25.13 & 35.34 & Iraklion & 0.33 & 6.28 & 34.93 & 0.910 & 6.09 & 25.97 & 0.431 \\
\hline 22.42 & 39.64 & Larissa & 0.38 & 6.30 & 20.77 & 0.922 & 6.13 & 14.68 & 0.690 \\
\hline 22.93 & 39.36 & Volos & 0.49 & 6.29 & 15.52 & 0.892 & 6.00 & 7.70 & 0.516 \\
\hline 20.86 & 39.67 & Ioannina & 0.27 & 6.30 & 23.51 & 0.947 & 6.06 & 22.05 & 0.781 \\
\hline 24.41 & 40.94 & Kavala & 0.26 & 6.43 & 42.50 & 1.018 & 6.09 & 41.97 & 1.022 \\
\hline 22.93 & 37.94 & Korinth & 0.64 & 6.30 & 13.57 & 0.969 & 5.94 & 5.47 & 0.759 \\
\hline 25.87 & 40.85 & Alexandroupolis & 0.32 & 6.32 & 31.57 & 0.845 & 5.98 & 19.37 & 0.653 \\
\hline 25.40 & 41.12 & Komotini & 0.21 & 6.35 & 44.16 & 0.850 & 6.09 & 46.35 & 0.870 \\
\hline 24.88 & 41.13 & Xanthi & 0.21 & 6.37 & 46.36 & 0.900 & 6.09 & 47.94 & 0.918 \\
\hline 24.15 & 41.15 & Drama & 0.28 & 6.29 & 27.09 & 0.804 & 6.06 & 18.87 & 0.422 \\
\hline 23.55 & 41.09 & Serres & 0.38 & 6.35 & 24.18 & 0.906 & 6.07 & 16.09 & 0.474 \\
\hline 22.87 & 40.99 & Kilkis & 0.54 & 6.28 & 13.10 & 0.840 & 6.04 & 9.29 & 0.635 \\
\hline 23.44 & 40.37 & Polygyros & 0.33 & 6.39 & 28.65 & 0.995 & 6.09 & 17.41 & 0.371 \\
\hline 24.24 & 40.25 & Karyai & 0.72 & 6.31 & 14.17 & 0.905 & 5.96 & 8.75 & 0.790 \\
\hline 22.04 & 40.80 & Edessa & 0.17 & 6.27 & 32.14 & 0.789 & 6.09 & 42.91 & 0.748 \\
\hline 22.20 & 40.52 & Veroia & 0.16 & 6.29 & 35.86 & 0.847 & 6.09 & 50.95 & 1.062 \\
\hline 22.50 & 40.27 & Katerini & 0.17 & 6.30 & 37.41 & 0.890 & 6.09 & 50.11 & 1.225 \\
\hline 21.40 & 40.78 & Florina & 0.17 & 6.27 & 30.14 & 0.800 & 6.04 & 16.31 & 0.288 \\
\hline 21.79 & 40.30 & Kozani & 0.16 & 6.30 & 35.63 & 0.867 & 6.08 & 30.43 & 0.782 \\
\hline 21.27 & 40.52 & Kastoria & 0.18 & 6.27 & 28.80 & 0.826 & 6.00 & 15.54 & 0.525 \\
\hline 21.42 & 40.08 & Grevena & 0.19 & 6.24 & 23.57 & 0.820 & 5.88 & 10.49 & 0.577 \\
\hline 20.98 & 39.16 & Arta & 0.65 & 6.28 & 12.10 & 0.980 & 6.01 & 8.14 & 0.814 \\
\hline 20.27 & 39.50 & Igoumenitsa & 0.40 & 6.27 & 17.59 & 0.933 & 5.95 & 6.87 & 0.527 \\
\hline 20.75 & 38.96 & Preveza & 0.73 & 6.32 & 12.98 & 1.029 & 5.95 & 5.52 & 0.844 \\
\hline 22.56 & 40.59 & Trikala & 0.20 & 6.33 & 36.07 & 0.901 & 6.09 & 31.69 & 0.882 \\
\hline 21.92 & 39.36 & Karditsa & 0.41 & 6.28 & 16.02 & 0.928 & 5.97 & 6.28 & 0.542 \\
\hline 23.60 & 38.46 & Halkis & 0.53 & 6.30 & 13.32 & 0.942 & 5.95 & 5.65 & 0.756 \\
\hline 22.43 & 38.90 & Lamia & 0.45 & 6.31 & 17.92 & 0.998 & 6.04 & 9.28 & 0.619 \\
\hline 22.88 & 38.43 & Levadia & 0.61 & 6.31 & 14.16 & 1.018 & 5.99 & 7.36 & 0.795 \\
\hline 22.38 & 38.53 & Amfissa & 0.67 & 6.32 & 13.18 & 1.024 & 5.99 & 7.51 & 0.849 \\
\hline 21.79 & 38.91 & Karpenision & 0.39 & 6.30 & 19.01 & 0.966 & 6.02 & 13.58 & 0.700 \\
\hline 21.43 & 38.37 & Messolongion & 0.44 & 6.30 & 18.18 & 1.024 & 6.08 & 21.44 & 1.107 \\
\hline 22.81 & 37.57 & Nafplio & 0.34 & 6.32 & 23.66 & 0.984 & 6.09 & 19.86 & 0.785 \\
\hline 21.44 & 37.67 & Pyrgos & 0.41 & 6.35 & 23.43 & 1.081 & 6.08 & 21.07 & 0.915 \\
\hline 22.37 & 37.51 & Tripoli & 0.29 & 6.28 & 24.37 & 0.927 & 6.09 & 27.84 & 0.782 \\
\hline 22.43 & 37.07 & Sparta & 0.29 & 6.31 & 29.38 & 0.985 & 5.90 & 15.59 & 1.011 \\
\hline 22.11 & 37.04 & Kalamata & 0.38 & 6.27 & 21.09 & 0.916 & 5.95 & 9.65 & 0.532 \\
\hline 25.71 & 35.19 & Agios & 0.34 & 6.25 & 29.20 & 0.892 & 5.98 & 18.81 & 0.690 \\
\hline 24.47 & 35.37 & Rethimno & 0.48 & 6.39 & 37.90 & 1.059 & 6.41 & 31.72 & 0.813 \\
\hline 24.02 & 35.51 & Chania & 0.54 & 6.42 & 37.78 & 1.109 & 6.37 & 30.42 & 0.937 \\
\hline 26.55 & 39.11 & Mythilini & 0.41 & 6.28 & 22.24 & 0.804 & 6.09 & 16.45 & 0.398 \\
\hline 26.14 & 38.36 & Xios & 0.27 & 6.26 & 23.99 & 0.786 & 6.09 & 13.68 & 0.180 \\
\hline 26.97 & 37.76 & Samos & 0.27 & 6.26 & 23.48 & 0.800 & 6.09 & 11.34 & 0.082 \\
\hline 24.94 & 37.44 & Ermoupolis & 0.13 & 6.25 & 48.06 & 0.767 & 6.09 & 72.13 & 1.041 \\
\hline 28.23 & 36.44 & Rodos & 0.39 & 6.26 & 25.19 & 0.837 & 6.05 & 23.53 & 0.777 \\
\hline 19.92 & 39.62 & Kerkyra & 0.30 & 6.24 & 16.49 & 0.863 & 5.98 & 7.86 & 0.473 \\
\hline 20.48 & 38.18 & Argostolion & 1.36 & 6.34 & 10.18 & 1.146 & 6.21 & 6.98 & 0.859 \\
\hline 20.71 & 38.83 & Lefkas & 0.80 & 6.33 & 12.57 & 1.088 & 6.08 & 7.19 & 0.784 \\
\hline 20.90 & 37.79 & Zakynthos & 0.88 & 6.29 & 12.38 & 1.040 & 5.96 & 5.47 & 0.776 \\
\hline
\end{tabular}


magnitude values, above 7.3 M. Therefore, the seismic hazard within a region of low seismicity is dominated by more distant events arising from one or multiple surrounding seismogenic sources.

The trend of the $\bar{\varepsilon}$ and $\widehat{\varepsilon}$ values, as illustrated on Fig. 3, is opposed to the observed trend for magnitude and distance. There is an overall tendency of decreasing the spatial distribution of the $\bar{\varepsilon}$ and $\widehat{\varepsilon}$ values as the response period increases from $0.2 \mathrm{~s}$ to $1.0 \mathrm{~s}$. Positive values of both $\bar{\varepsilon}$ and $\widehat{\varepsilon}$ are observed for almost all the grid points. The negative values are reported only for $\widehat{\varepsilon}$ and are mostly observed at intermediate periods. This might indicate that at those locations the estimated $\mathrm{SA}(1.0 \mathrm{~s})$ is below the median $\mathrm{SA}(1.0 \mathrm{~s})$ computed from the modal scenario defined by the M-R pair. On contrary, the positive $\bar{\varepsilon}$ and $\widehat{\varepsilon}$ values are likely to produce ground motion above the median. Also, $\widehat{\varepsilon}$ presents a greater geographical variance over the region than $\bar{\varepsilon}$. The largest $\bar{\varepsilon}$ and $\widehat{\varepsilon}$ values are concentrated in regions of high seismicity, characterized by larger, closer, and/or more frequent earthquakes.

With the aim of these maps, one might identify one or multiple scenarios for a particular grid point, from the corresponding $\bar{M}, \bar{R}$ and $\bar{\varepsilon}$ and/or ( $\widehat{M}, \widehat{R}$ and $\widehat{\varepsilon}$ ) triplet reported on these maps. The corresponding $\bar{M}, \bar{R}$ and $\bar{\varepsilon}$ and/or ( $\widehat{M}$, $\widehat{R}$ and $\widehat{\varepsilon}$ ) values were determined for 50 Greek municipalities as summarized in Table $2 \mathrm{a}$ and $\mathrm{b}$. These results indicate that for most of the selected cities, the hazard is from close distance $(<40 \mathrm{~km})$ and moderate earthquakes $(M<6.5)$. One aspect associated with these values used to define dominant scenarios is that, when the M-R- $\varepsilon$ triplet is incorporated into the predictive equation, the identified scenarios might generate the target ground motion level, or will exceed the target ground motion level. It is important to note that the present deaggregation methodology, considers that the identified scenario, defined by the M-R- $\varepsilon$ triplet, will exceed the target ground motion level. Harmsen and Frankel (2001) as well as, Bazzurro and Cornell (1999) have shown that for some regions in the western United States, the range of exceedance of the target ground motion level was small, with values ranging within $15-20 \%$ of the median value.

\section{Conclusions}

The disaggregation of hazard into relative contributions from different sources and earthquake events achieves an important two-fold result: better insights and improved communication of the hazard, and a more informed characterization of the ground motion to be expected at the site. These techniques are intended to support further engineering analyses which require information that goes beyond the knowledge of the likelihood of different ground motion intensities at the site.

A common application where such disaggregation results can be useful is in the development of ground motion accelerograms for design or rehabilitation of structures lo- cated at specific sites. A hazard-consistent selection process would remove that degree of arbitrariness which is otherwise unavoidable. From an earthquake engineering perspective, these deaggregation maps might provide a basis for selecting recorded acceleration time histories for special buildings that requests extensive structural analyses, such as nonlinear dynamic analysis. In this respect, the national seismic codes might be accompanied by such deaggregation maps. In this study, the seismic hazard was de-aggregated at $0.2 \mathrm{~s}, 0.4 \mathrm{~s}$, and $1 \mathrm{~s}$ at the $10^{-3}$ exceedance level. These results can then be used to select analysis and design parameters, as appropriate.

Edited by: M. E. Contadakis

Reviewed by: E. Lekkas and another anonymous referee

\section{References}

Bazzurro, P.: Probabilistic Seismic Demand Analysis, Ph.D. thesis, Stanford University, 1998.

Bazzurro, P. and Cornell, A. C.: Dissagregation of Seismic Hazard, B. Seismol. Soc. Am., 89(2), 501-520, 1999.

Chapman, M. C.: A probabilistic approach to ground motion selection for engineering design, B. Seismol. Soc. Am., 85(3), 937942, 1995.

Cornell, C. A.: Engineering Seismic Risk Analysis, B. Seismol Soc. Am., 58, 1583-1606, 1968.

Cramer, C. H. and Petersen, M. D.: Predominant Seismic Source Distance and Magnitude Maps for Los Angeles, Orange and Ventura Counties, California, B. Seismol. Soc. Am., 86(5), 16451649, 1996.

Esteva, L.: Seismic Risk and Seismic Design Decisions, in: Seismic Design for Nuclear Power Plants, edited by: Hansen, R. J., Massachusetts Inst. of Tech. Press, Cambridge, MA, USA, 142-82, 1970.

Halchuck, S. and Adams, J.: Deaggregation of seismic hazard for selected Canadian cities, XIII World Conference on Earthquake Engineering, Vancouver, Canada, 1-6, August 2004.

Halchuck, S., Adams, J., and Anglin, F.: Revised Deaggregation of Seismic Hazard for Selected Canadian Cities, Ninth Canadian Conference on Earthquake Engineering Ottawa, Ontario, Canada, Paper 1188, 26-29, June 2007.

Harmsen, S. and Frankel, A.: Geographic Deaggregation of Seismic Hazard in the United States, B. Seismol. Soc. Am., 91(1), 13-26, 2001.

Harmsen, S., Perkins, D., and Frankel, A.: Deaggregation of probabilistic ground motions in the central and eastern United States, B. Seismol. Soc. Am., 89(1), 1-13, 1999.

Harmsen, S. C.: Mean and Modal $\varepsilon$ in the Deaggregation of Probabilistic Ground Motion, B. Seismol. Soc. Am., 91(6), 15731552, 2002.

McGuire, R. K. and Shedlock, K. M.: Statistical uncertainties in seismic hazard evaluations in the United States, B. Seismol. Soc. Am., 71(4), 1287-1308, 1981.

Montilla, J. A. P., Casado, C. L., and Romero, J. H.: Deaggregation in Magnitude, Distance, and Azimuth in the South and West of the Iberian Peninsula, B. Seismol. Soc. Am., 92(6), 2177-2185, 2002. 
Pagani, M. and Marcellini, A.: Seismic-Hazard Disaggregation: A fully Probabilistic Methodology, B. Seismol. Soc. Am., 97(5), 1688-1701, 2007.

Smith, W. D.: On Assessment and Disaggregation of Seismic Risk, B. Seismol. Soc. Am., 98(2), 793-796, 2008.

Stepp, J. C., Silva, W. J., McGuire, R. K., and Sewell, R. T.: Determination of earthquake design loads for a high level nuclear waste repository facility, Proc. 4th DOE natural Phen. Haz. Mitig. Conf., Atlanta, 651-657, 1993.
Tselentis, G-A. and Danciu, L.: Probabilistic seismic hazard assessment in Greece - Part 1: Engineering ground motion parameters, Nat. Hazards Earth Syst. Sci., 10, 25-39, 2010, http://www.nat-hazards-earth-syst-sci.net/10/25/2010/.

Tselentis, G-A., Danciu, L., and Sokos, E.: Probabilistic seismic hazard assessment in Greece - Part 2: Acceleration response spectra and elastic input energy spectra, Nat. Hazards Earth Syst. Sci., 10, 41-49, 2010,

http://www.nat-hazards-earth-syst-sci.net/10/41/2010/. 